\title{
Key Clinical Adverse Events in Patients with Advanced Basal Cell Carcinoma Treated with Sonidegib or Vismodegib: A Post Hoc Analysis
}

\author{
Ralf Gutzmer (D) · Carmen Loquai · Caroline Robert · Brigitte Dréno • \\ Alexander Guminski · Karl Lewis · Ramon Arntz · Serena Martelli • \\ Nicholas Squittieri · Meenal Kheterpal
}

Received: May 27, 2021 / Accepted: July 29, 2021 / Published online: September 6, 2021

(C) The Author(s) 2021

\section{ABSTRACT}

Introduction: Sonidegib is approved to treat locally advanced basal cell carcinoma (laBCC) in the USA, EU, Switzerland, and Australia and metastatic basal cell carcinoma (mBCC) in Switzerland and Australia in patients not amenable to surgery or radiotherapy. Vismodegib is approved to treat patients with mBCC, recurrent laBCC, or those not candidates for surgery or radiation. There is no head-to-head trial comparing Hedgehog inhibitors. We describe time to onset and severity of adverse

R. Gutzmer $(\bowtie)$

Skin Cancer Center Minden, Department of Dermatology, Johannes-Wesling-Klinikum Minden/ Ruhr-University Bochum, Minden, Germany e-mail: rgutzmer@gmx.de

\section{Loquai}

University Medical Center Mainz, Mainz, Germany

C. Robert

Institut Gustave Roussy and Paris-Saclay University, Villejuif, France

B. Dréno

Department of Dermatology, University Hospital

Nantes, CIC 1413, CRCINA, Nantes, France

A. Guminski

Royal North Shore Hospital, Sydney, Australia

A. Guminski

The University of Sydney, Sydney, Australia events (AEs) in two studies reporting cumulative $\mathrm{AE}$ incidence every treatment cycle: the sonidegib phase 2 BOLT study and the expanded-access, open-label vismodegib study.

Methods: This analysis included patients with histologically confirmed laBCC or mBCC from BOLT who received sonidegib $200 \mathrm{mg}$ once daily (QD) and patients from the vismodegib study who received vismodegib $150 \mathrm{mg}$ QD. Cumulative occurrence of AEs and median time to AE onset were calculated on 30-day cycles for sonidegib and 28-day cycles for vismodegib. AEs were graded for severity using the Common Terminology Criteria for Adverse Events. Only

\section{K. Lewis}

University of Colorado Cancer Center, Anschutz

Medical Campus, Aurora, CO, USA

R. Arntz · S. Martelli

Sun Pharmaceutical Industries, (Europe) B.V., Hoofdorp, North Holland, Netherlands

\section{N. Squittieri}

Sun Pharmaceutical Industries, Inc., Princeton, NJ, USA

\section{Kheterpal}

Duke Health, Duke University, Durham, NC, USA 
common (at least 15\% incidence) AEs were analyzed in this study.

Results: Over 18 treatment cycles, the most common all-grade AEs for sonidegib and vismodegib were muscle spasm $(54.4 \%$ vs $70.6 \%$; $P=0.0236)$, alopecia $(49.4 \%$ vs $58.0 \%$; no significant difference [NS]), and dysgeusia $(43.0 \%$ vs $70.6 \% ; P=0.0003$ ); incidences of diarrhea, nausea, fatigue, and weight decrease were $31.6 \%$ vs $25.2 \%$ (NS), $39.2 \%$ vs $19.3 \%$ $(P=0.0032), 32.9 \%$ vs $19.3 \%(P=0.0429)$, and $30.4 \%$ vs $16.0 \% \quad(P=0.0217)$, respectively. Sonidegib-treated patients had more delayed median time to onset for all AEs than vismodegib-treated patients, except fatigue and weight decrease (NS). Most AEs reported were grade $\leq 2$.

Conclusion: This post hoc analysis suggests lower overall incidence and slower onset of certain AEs in patients treated with sonidegib compared with vismodegib. In the absence of head-to-head comparisons, the relevance of these findings needs further studies to provide conclusive evidence.

Keywords: Basal cell carcinoma; Sonidegib; Vismodegib; Hedgehog inhibitors; Adverse event onset

\section{Key Summary Points}

\section{Why carry out this study?}

Clinical differences between sonidegib and vismodegib in patients with locally advanced basal cell carcinoma or metastatic basal cell carcinoma remain unclear as there are no head-to-head clinical trials comparing these Hedgehog inhibitors

This post hoc analysis describes the time to onset and severity of treatmentemergent adverse events in patients in the BOLT pivotal trial for sonidegib and patients in the expanded access, openlabel study for vismodegib

\section{What was learned from this study?}

Patients treated with sonidegib had a later median time to onset for all adverse events than patients treated with vismodegib, with the exception of fatigue and weight decrease

Adverse events with both treatments were primarily low grade (grade $\leq 2$ )

This post hoc analysis described differences between sonidegib and vismodegib furthering the understanding of trends relative to their safety profiles; additional studies are needed to confirm the relevance of these findings

\section{INTRODUCTION}

Basal cell carcinoma (BCC) is the most common human malignancy; its prevalence increases worldwide with Caucasian populations at highest risk [1-3]. The majority of BCC cases are slow growing and can be treated effectively with surgery, topical therapy, or radiation therapy $[4,5]$. However, certain BCCs can become invasive and destructive locally advanced BCCs (laBCCs) or metastatic BCCs (mBCCs) with malignancies no longer amenable to primary treatment options [6].

A key driver of BCC pathogenesis and growth is abnormal activation of the Hedgehog signaling pathway, most often resulting from mutations in the patched 1 gene (PTCH1) or the Smoothened (SMO) transmembrane protein [7-9]. For patients with laBCC or mBCC where surgery is contraindicated or unlikely to be effective, systemic Hedgehog inhibitors (HHIs) are the recommended therapy [4].

Sonidegib (Odomzo®; Sun Pharmaceutical Industries, Inc.; Cranbury, NJ) and vismodegib (Erivedge ${ }^{\circ}$; Genentech, Inc.; San Francisco, $\mathrm{CA})$, both HHIs, target SMO and are approved for treatment of advanced BCC (aBCC) [10, 11]. Sonidegib is approved to treat patients with laBCC in the USA, EU, Switzerland, and Australia and $\mathrm{mBCC}$ in Switzerland and Australia in 
patients not amenable to surgery or radiotherapy $[10,12-14]$. Vismodegib is approved to treat patients with mBCC, recurrent laBCC, or who are not candidates for surgery or radiation in the USA, EU, Switzerland, and Australia $[11,13,15,16]$.

There are currently no head-to-head clinical studies comparing sonidegib and vismodegib. Therefore, clinical differences between sonidegib and vismodegib in patients with laBCC or mBCC remain unclear. Without direct comparisons between HHIs, a post hoc analysis describing differences between treatments is valuable in understanding trends relative to their safety profiles. This post hoc analysis describes the time to onset and severity of adverse events (AEs) in patients in the pivotal phase 2 Basal cell carcinoma Outcomes with LDE225 (sonidegib) Treatment (BOLT) study for sonidegib and patients in the expanded access, open-label study for vismodegib.

\section{METHODS}

\section{Study Design}

This analysis utilized datasets from BOLT and the vismodegib study, which included cumulative $\mathrm{AE}$ incidence reported every treatment cycle. Details about the study design and primary results of both studies are previously published [8, 17-19]. Briefly, BOLT was a randomized, multicenter, double-blind phase 2 study (ClinicalTrials.gov, NCT01327053) that enrolled adults with histologically confirmed laBCC or mBCC not amenable to curative surgery, radiation therapy, or other local therapies [17]. Patients were randomized in a $1: 2$ ratio to sonidegib 200 or $800 \mathrm{mg}$ once daily (QD) with randomization stratified by disease stage (laBCC or $\mathrm{mBCC}$ ), histological subtype (aggressive or nonaggressive for laBCC), and geographical region. The vismodegib study (ClinicalTrials.gov, NCT01160250) was an open-label, nonrandomized, multicenter study that enrolled adults with histologically confirmed laBCC or mBCC deemed inoperable or contraindicated for surgery [8].
Safety assessments in both studies included $\mathrm{AE}$ monitoring of all patients receiving at least one dose of the study drug. AEs were coded using Medical Dictionary for Regulatory Activities (MedDRA) terminology and graded for severity using the National Cancer Institute's Common Terminology Criteria for Adverse Events (version 4.0) [20]. AE recording occurred every one to two treatment cycles in the vismodegib study; in BOLT, AEs were continuously monitored during the study and up to 30 days post-study discontinuation, with AEs recorded at each study visit, between visits, or during other assessments, as applicable.

After approval from institutional review boards, and in accordance with Declaration of Helsinki guidelines, all patients in both studies provided written informed consent and continued study treatment until disease progression, unacceptable toxicity, death, study termination, or withdrawal of consent.

\section{Statistical Analysis}

Only the regulatory-approved $200 \mathrm{mg}$ treatment arm from BOLT was included in this study. The cumulative occurrence and time to onset of treatment-emergent AEs (TEAEs) were calculated on a 30-day treatment cycle for sonidegib and a 28-day treatment cycle for vismodegib [8]. Corresponding 95\% confidence intervals (CI) were calculated for sonidegib, but these data were not available for vismodegib. Raw data for cumulative TEAE incidence over individual treatment cycles from the vismodegib study were not published; AE data presented in this analysis were estimated from the results published in the vismodegib study [8]. No direct statistical comparisons of TEAE occurrence or severity were evaluated between sonidegib and vismodegib.

Binary demographics and baseline characteristics were compared between the treatments using a two-sided Fisher's exact test. The Eastern Cooperative Oncology Group performance status was compared between treatments using a $\chi^{2}$ test.

For comparisons between sonidegib and vismodegib with respect to the binary $\mathrm{AE}$ rates, 
two-sided Fisher's exact tests were used. As the raw time-to-event data of AEs were not available for vismodegib, hazard ratios and their $95 \% \mathrm{Cls}$ were derived on the basis of the median time to event and the number of events in both groups [21]. The respective $P$ values were computed using a previously described approach [22].

\section{RESULTS}

\section{Patient Disposition and Characteristics}

As previously published, the BOLT study had 79 patients randomized to sonidegib $200 \mathrm{mg}$; all were included in this analysis. Of the 120 patients enrolled in the vismodegib study, 119 were included in this analysis; one patient was lost to follow-up. Demographics and baseline

Table 1 Demographics and baseline clinical characteristics

\begin{tabular}{llll}
\hline & $\begin{array}{l}\text { Sonidegib } \\
\mathbf{2 0 0} \mathbf{~ m g} \\
(\boldsymbol{n}=\mathbf{7 9})\end{array}$ & $\begin{array}{l}\text { Vismodegib } \\
\mathbf{1 5 0} \mathbf{~ m g} \\
(\boldsymbol{n}=\mathbf{1 1 9})\end{array}$ & $\boldsymbol{P}$ value \\
\hline $\begin{array}{l}\text { Age, years, } \\
\text { median } \\
\text { (range) }\end{array}$ & $67.0(25-92)$ & $62.0(24-100)$ & $\mathrm{N} / \mathrm{A}$ \\
$\begin{array}{l}\text { Sex, male } \\
\text { ECOG performance status }\end{array}$ & $48(60.8)$ & $88(73.9)$ & $0.0607^{*}$ \\
0 & $50(63.3)$ & $69(58.0)$ & $0.1515^{\dagger}$ \\
1 & $19(24.1)$ & $41(34.5)$ & \\
2 & $8(10.1)$ & $9(7.6)$ & \\
Unknown & $2(2.5)$ & 0 & \\
Stage & & & \\
laBCC & $66(83.5)$ & $62(52.1)$ & $<0.0001^{*}$ \\
mBCC & $13(16.5)$ & $57(47.9)$ & \\
\hline
\end{tabular}

$B C C$ basal cell carcinoma, ECOG Eastern Cooperative Oncology Group, laBCC locally advanced BCC, $m B C C$ metastatic BCC, $N / A$ not available

Data presented as $n$ (\%) of patients unless otherwise indicated

${ }^{*}$ Two-sided Fisher's exact test

$\dagger \chi^{2}$ test, two-sided clinical characteristics for both cohorts are summarized in Table 1 . The vismodegib study had more patients with mBCC (47.9\%) than the sonidegib BOLT study (16.5\%).

\section{Onset and Severity of Adverse Events}

Common (defined as at least 15\% incidence) TEAEs investigated in this study were alopecia, dysgeusia, muscle spasms, diarrhea, nausea, fatigue, and weight decrease. Over 18 treatment cycles, the most common all-grade TEAEs for both sonidegib and vismodegib were muscle spasm $(54.4 \%$ vs $70.6 \%$, respectively; $P=0.0236)$, alopecia $(49.4 \%$ vs $58.0 \%$, respectively; no significant difference [NS]), and dysgeusia $\quad(44.3 \%$ vs $70.6 \%$, respectively; $P=0.0003$ ) (Fig. 1 and Table 2). The overall cumulative TEAE rates for diarrhea, nausea, fatigue, and weight decrease in sonidegib and vismodegib were $31.6 \%$ vs $25.2 \%$ (NS), $39.2 \%$ vs $19.3 \% \quad(P=0.0032), \quad 32.9 \% \quad$ vs $\quad 19.3 \%$ $(P=0.0429)$, and $30.4 \%$ vs $16.0 \%(P=0.0217)$, respectively (Fig. 1 and Table 2).

Almost all patients receiving vismodegib $(97.5 \%)$ or sonidegib (97.5\%) experienced at least one TEAE. Figure 1 shows the cumulative onset of TEAEs over 18 cycles of treatment. Patients receiving vismodegib experienced earlier time to onset than those receiving sonidegib for all TEAEs, with the exception of fatigue and weight decrease (both NS) (Table 3). With sonidegib $200 \mathrm{mg}$, fatigue had the shortest median time to onset at 1.1 months (95\% CI 0.5-3.7), followed by muscle spasm at 2.1 months (95\% CI 1.9-3.2). Diarrhea and weight decrease had the longest median times to onset, both 6.5 months. With vismodegib $150 \mathrm{mg}$, nausea had the shortest median time to onset at 1.0 month (95\% CI 0.4-4.3), followed by muscle spasm at 1.2 months (95\% CI 0.9-1.5). Alopecia and weight decrease had the longest median times to onset, at 2.9 and 5.8 months, respectively.

Patients treated with both sonidegib $200 \mathrm{mg}$ and vismodegib $150 \mathrm{mg}$ primarily experienced TEAEs that were low in severity (grade $\leq 2$ ). In the vismodegib study, $4(3.4 \%)$ patients had grade 3 TEAEs: $2(1.7 \%)$ patients with muscle 


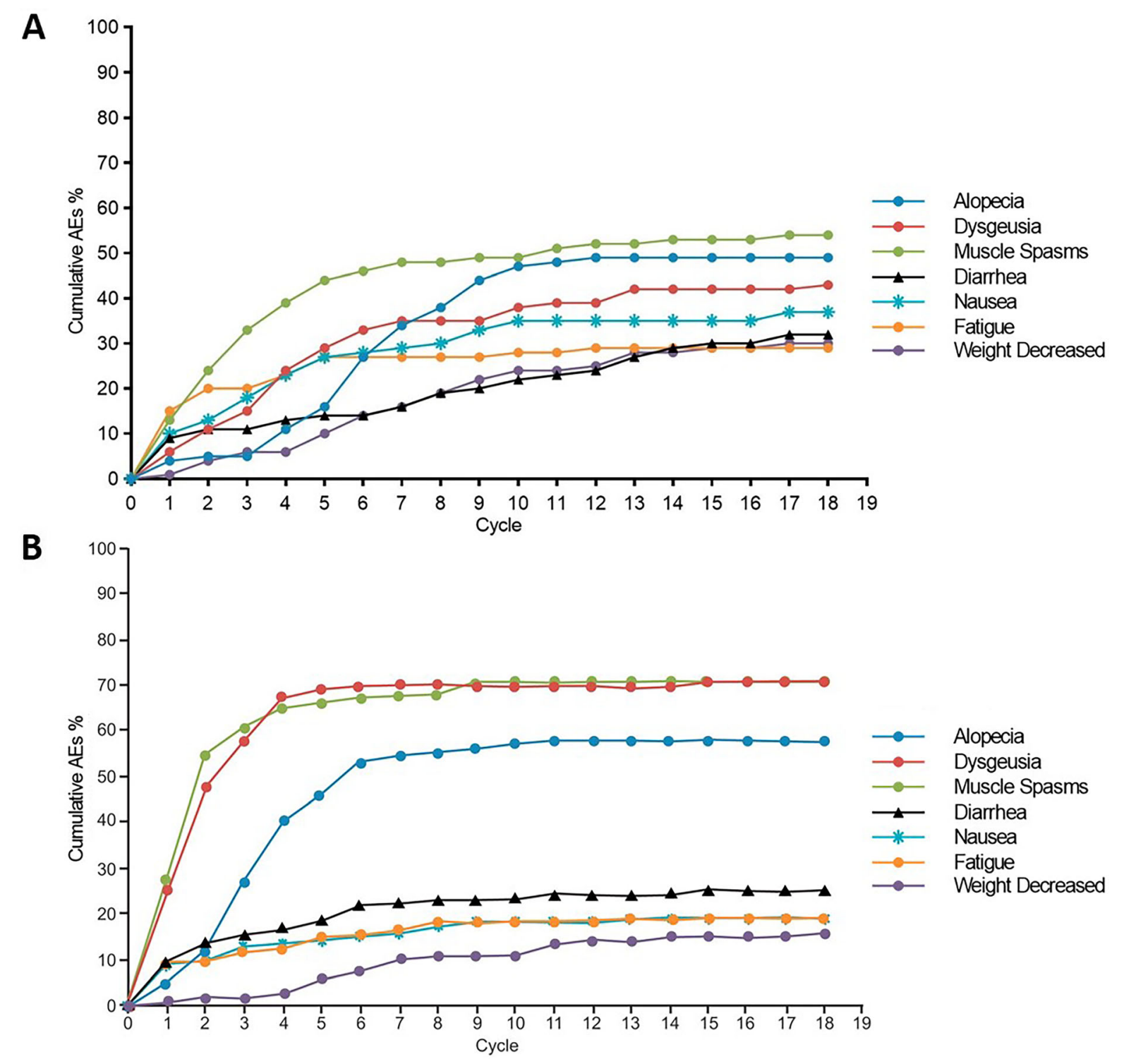

Fig. 1 Cumulative onset of treatment-emergent adverse events over all treatment cycles in patients receiving $\mathbf{A}$ sonidegib $200 \mathrm{mg}$ daily and $\mathbf{B}$ vismodegib $150 \mathrm{mg}$ daily. Reproduced with permission from [8]

spasms, $1(0.8 \%)$ with diarrhea, and $1(0.8 \%)$ with fatigue (Table 2$)$. There was $1(0.8 \%)$ patient that reported a grade 4 TEAE of diarrhea in the vismodegib study. In BOLT, $9(11.4 \%)$ patients had grade 3 TEAEs; there were no grade 4 TEAEs (Table 2). The most common grade 3 TEAE in sonidegib patients was decreased weight $(n=4[5.1 \%])$.

\section{DISCUSSION}

Sonidegib and vismodegib are HHIs indicated for the treatment of aBCC. Clinical differences between sonidegib and vismodegib are unclear, as there are no direct head-to-head clinical trials. Furthermore, there are no evidence-based recommendations to help clinicians choose between them when treating patients with aBCC [23]. This post hoc analysis described the time to onset and severity of TEAEs in patients 


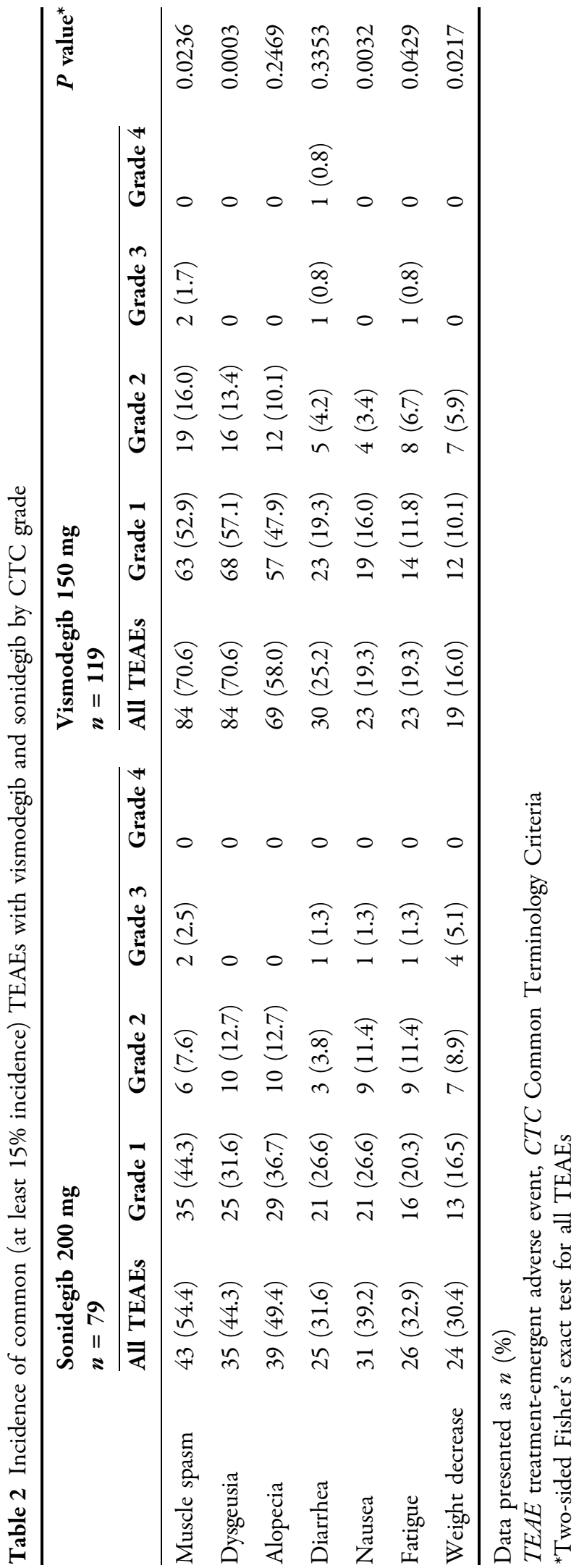

treated with sonidegib $200 \mathrm{mg}$ and patients treated with vismodegib $150 \mathrm{mg}$. A lower incidence of muscle spasm, alopecia, and dysgeusia was found in patients taking sonidegib, who conversely had a slightly higher incidence of nausea, fatigue, diarrhea, and weight decrease compared with those who received vismodegib. Onset of TEAEs was faster in vismodegib-treated patients than those treated with sonidegib for all TEAEs except fatigue and weight decrease (both NS); TEAEs with both treatments were primarily low in severity.

Muscle spasm, alopecia, and dysgeusia are consistently reported as the most frequent AEs that occur with both HHIs [24-27]. The incidence rates of these common AEs are comparable across multiple published clinical studies in patients with aBCC treated with HHIs. In the vismodegib pivotal phase 2 , randomized, controlled aBCC trial (ERIVANCE), the most common AEs were muscle spasms (71.2\%), alopecia (66.3\%), and dysgeusia (55.8\%) [24]. Similarly, the phase 2, open-label STEVIE trial demonstrated muscle spasms (66\%), alopecia (62\%), and dysgeusia (55\%) as the most common AEs of patients receiving vismodegib $150 \mathrm{mg}$ QD [26]. The incidence rates from ERIVANCE and STEVIE are in alignment with those for vismodegib and higher than those for sonidegib in this post hoc analysis. This consistency suggests that muscle spasms, alopecia, and dysgeusia may be class effects associated with targeted inhibition of the Hedgehog signaling pathway [25].

The proportion of high-grade TEAEs reported in this analysis and in the Chang et al. study for vismodegib patients (4.2\%) is lower than previously reported. In ERIVANCE, $22.1 \%$ of patients experienced grade 3 or 4 severity of the common TEAEs included in this analysis. Similarly, $17.9 \%$ of patients in STEVIE reported TEAEs. Differences in AE severity reported with vismodegib may be due to differences in study design, frequency, and type of $\mathrm{AE}$ monitoring and recording, participant population, or length of treatment duration. While fewer highgrade AEs were observed with vismodegib than with sonidegib (4.2\% and $11.4 \%$, respectively), it should be noted that this difference is mainly driven by grade 3 weight decrease with 
Table 3 Median time to onset (95\% CI) of common treatment-emergent adverse events

\begin{tabular}{|c|c|c|c|c|c|}
\hline & \multicolumn{2}{|l|}{$\begin{array}{l}\text { Sonidegib } 200 \mathrm{mg} \\
n=79\end{array}$} & \multicolumn{2}{|l|}{$\begin{array}{l}\text { Vismodegib } 150 \mathrm{mg} \\
n=119\end{array}$} & \multirow[t]{2}{*}{$\begin{array}{l}\text { HR }(95 \% \mathrm{CI}) \\
P \text { value }\end{array}$} \\
\hline & $\begin{array}{l}\text { Median time to onset } \\
\text { (95\% CI), months }\end{array}$ & $\begin{array}{l}\text { Number of } \\
\text { events }\end{array}$ & $\begin{array}{l}\text { Median time to onset } \\
(95 \% \mathrm{CI}) \text {, months }\end{array}$ & $\begin{array}{l}\text { Number of } \\
\text { events }\end{array}$ & \\
\hline \multirow[t]{2}{*}{ Muscle spasm } & $2.1(1.9-3.2)$ & 43 & $1.2(0.9-1.5)$ & 84 & $0.57(0.40-0.83)$ \\
\hline & & & & & 0.0029 \\
\hline \multirow[t]{2}{*}{ Dysgeusia } & $3.7(2.8-4.9)$ & 35 & $1.4(1.0-1.7)$ & 84 & $0.38(0.26-0.56)$ \\
\hline & & & & & $<0.0001$ \\
\hline \multirow[t]{2}{*}{ Alopecia } & $5.5(4.7-6.4)$ & 39 & $2.9(2.5-3.5)$ & 69 & $0.53(0.36-0.78)$ \\
\hline & & & & & 0.0014 \\
\hline \multirow[t]{2}{*}{ Diarrhea } & $6.5(1.3-10.3)$ & 25 & $1.3(0.7-3.9)$ & 30 & $0.20(0.12-0.34)$ \\
\hline & & & & & $<0.0001$ \\
\hline \multirow[t]{2}{*}{ Nausea } & $3.2(1.5-4.6)$ & 31 & $1.0(0.4-4.3)$ & 23 & $0.31(0.18-0.54)$ \\
\hline & & & & & $<0.0001$ \\
\hline \multirow[t]{2}{*}{ Fatigue } & $1.1(0.5-3.7)$ & 26 & $1.4(0.5-4.0)$ & 23 & $1.27(0.73-2.23)$ \\
\hline & & & & & 0.4068 \\
\hline \multirow[t]{2}{*}{ Weight decrease } & $6.5(4.7-8.3)$ & 24 & $5.8(3.8-9.8)$ & 19 & $0.89(0.49-1.63)$ \\
\hline & & & & & 0.7237 \\
\hline
\end{tabular}

$C I$ confidence interval, $H R$ hazard ratio

sonidegib, occurring in $5.1 \%$ of patients; 0 vismodegib-treated patients experienced grade 3 weight decrease (Table 2). Interestingly, in STEVIE, most TEAEs leading to treatment discontinuation were low in severity (grade $\leq 2$ ). This emphasizes that AE severity is not the only factor playing a role in treatment discontinuation. Frequency, duration, and disturbance to daily life, among other factors, may also affect the decision to discontinue treatment.

Over 18 treatment cycles, a slightly higher cumulative incidence and rate of onset for nausea, fatigue, diarrhea, and weight decrease were observed in patients treated with sonidegib than with vismodegib. These findings from the current post hoc analysis suggest a slightly lower incidence of nausea, fatigue, diarrhea, and weight decrease with vismodegib than sonidegib, but a greater incidence of muscle spasm, alopecia, and dysgeusia. Muscle spasm, alopecia, weight loss, and dysgeusia are the most frequently reported AEs by patients taking HHIs and commonly lead to treatment discontinuation [17, 24, 27]. Therefore, reducing the incidence of these AEs may have the greatest clinical impact on aBCC treatment.

Investigation of the time to onset of TEAEs revealed that patients treated with sonidegib may experience later onset of most AEs than patients treated with vismodegib (Fig. 1). In patients receiving vismodegib, median time to onset of most TEAEs was less than 2 months after treatment initiation. The sharp incidence of these AEs was not observed in patients receiving sonidegib. After only three treatment cycles, the cumulative rates of muscle spasm, dysgeusia, and alopecia were approximately $60 \%, 60 \%$, and $25 \%$, respectively, in patients receiving vismodegib, while these rates were $32.9 \%, 15.2 \%$, and $5.1 \%$, respectively, in 
patients receiving sonidegib. Slower time to $\mathrm{AE}$ onset may be associated with delayed treatment discontinuation from AEs and subsequently increased treatment duration, although direct comparative studies are needed to confirm these findings and provide evidence for this hypothesis.

Although clinical studies of sonidegib and vismodegib in patients with laBCC have demonstrated positive efficacy results, the high frequency of AEs experienced by patients undergoing treatment continues to be of concern $[8,17,24]$. Multiple clinical studies report over $97 \%$ of patients receiving an HHI experience at least one AE over the course of treatment, and the percentage that discontinue treatment because of AEs is as high as 31\% $[17,24,26,27]$. Improved understanding of incidence and time to onset of TEAEs in patients with aBCC treated with HHIs may lead to reduced treatment discontinuation and ultimately assist clinicians with treatment decisions.

Differences observed in the frequency and time of onset of TEAEs during treatment with sonidegib and vismodegib may be due to the differences in pharmacokinetic (PK) profiles. Sonidegib reaches peak plasma concentration within $2-4 \mathrm{~h}$ of dosing, while vismodegib peak plasma concentration occurs approximately 2 days after a single dose [28, 29]. Additionally, vismodegib has an elimination half-life of 4-12 days and a volume of distribution of approximately 16-27 L [11], while sonidegib has an elimination half-life of 30-41 days and a volume of distribution of approximately 9000-34,000 L [28, 30]. These values suggest that vismodegib is largely confined to the plasma and has limited tissue penetration, whereas sonidegib has extensive tissue distribution. Additionally, steady-state levels of sonidegib are six times higher in the skin than in plasma [12]. These pharmacological differences between sonidegib and vismodegib may contribute to the observed differences in TEAE onset.

Several factors should be considered when interpreting findings from this post hoc analysis. Most notably, study design and patient characteristics differed distinctly between the
BOLT and vismodegib studies; therefore, direct comparisons between studies and treatments cannot be made. Although it was not possible to make statistical comparisons in this post hoc analysis, given the limited clinical data available for sonidegib and vismodegib, indirect comparisons may still provide value to clinicians to further understand these therapies. Both the BOLT sonidegib $200 \mathrm{mg}$ group and the Chang et al. vismodegib study had relatively small sample sizes, with fewer patients enrolled in BOLT. Vismodegib data from the large ERIVANCE and STEVIE studies could not be included in this brief report, as time to TEAE onset data for vismodegib was not reported in these studies. Additionally, the majority of patients in BOLT had laBCC rather than mBCC $(83.5 \%$ vs $16.5 \%$, respectively), whereas the vismodegib study was more equally distributed $(52.1 \%$ vs $47.9 \%$, respectively). Lastly, the vismodegib treatment cycle was 28 days, while the sonidegib treatment cycle was 30 days, possibly leading to slightly different treatment effects when examining TEAEs by treatment cycle.

\section{CONCLUSIONS}

This study provides insight into the onset of TEAEs in patients with aBCC treated with sonidegib or vismodegib HHIs. This post hoc analysis suggests a delayed onset of many common TEAEs and lower incidence of muscle spasm, alopecia, and dysgeusia in patients treated with sonidegib $200 \mathrm{mg}$ compared with vismodegib $150 \mathrm{mg}$. TEAEs with both treatments were primarily low grade (grade $\leq 2$ ). In the absence of a head-to-head comparison study, the relevance of these findings needs further studies to provide conclusive evidence.

\section{ACKNOWLEDGEMENTS}

Funding. This post hoc analysis and the journal's rapid service fee were sponsored and funded by Sun Pharmaceutical Industries, Inc. (Princeton, NJ, USA). 
Authorship. All authors meet the International Committee of Medical Journal Editors (ICMJE) criteria for authorship for this article, take responsibility for the integrity of the work as a whole, and have given their approval for this version to be published.

Author Contributions. RA, SM, and NS contributed to the study design and implementation of the research. RG, CL, CR, BD, AG, $\mathrm{KL}$, RA, SM, NS, and MK drafted and/or critically reviewed the manuscript and approved the manuscript for submission.

Medical Writing, Editorial, and Other Assistance. Writing and editorial support for manuscript preparation were provided by Margaret Van Horn, PhD (AlphaBioCom, LLC, King of Prussia, PA), and funded by Sun Pharmaceutical Industries, Inc.

Disclosures. Ralf Gutzmer serves as consultant to Almirall; Amgen; Bristol-Myers Squibb; Merck Serono; Merck Sharp \& Dohme; Novartis; Pfizer; Pierre Fabre; Roche; Sanofi Genzyme; Sun Pharmaceutical Industries, Inc.; and 4SC; has received travel grants and honoraria for lectures from Almirall; Amgen; Bayer; Bristol-Myers Squibb; Merck Serono; Merck Sharp \& Dohme; Novartis; Pierre Fabre; Roche; Sanofi Genzyme; and Sun Pharmaceutical Industries, Inc.; and received research funding from Amgen; Johnson \& Johnson; Merck Serono; Novartis; Sanofi; and Sun Pharmaceutical Industries, Inc. Carmen Loquai acted as a speaker for, participated in an advisory board for, and received honoraria from Bristol-Myers Squibb, Roche, Novartis, and Merck Sharp \& Dohme. Caroline Robert has received consulting fees from Amgen, Array BioPharma, Bristol-Myers Squibb, Merck, Merck Serono, Novartis, Pierre Fabre, and Roche. Brigitte Dréno has been a consultant or advisor for Bristol-Myers Squibb, GlaxoSmithKline, Roche, and Novartis; has served on speakers' bureaus for Bristol-Myers Squibb, GlaxoSmithKline, and Roche; has received research funding from Amgen, Bristol-Myers Squibb, and GlaxoSmithKline; and has received travel support from Bristol-Myers Squibb, and Roche. Alexander Guminski has participated on advisory boards for Bristol-Myers Squibb, Pfizer, and Sanofi; received honoraria from Novartis Pharmaceuticals Corporation; and received travel support from Astellas; Bristol-Myers Squibb; and Sun Pharmaceutical Industries, Inc. Karl Lewis has received grants and personal fees from Amgen; Bristol-Myers Squibb; Genentech; GlaxoSmithKline; Merck Sharp \& Dohme; Novartis; and Roche. Ramon Arntz and Serena Martelli are employees of Sun Pharmaceutical Industries, (Europe) B.V. Nicholas Squittieri is an employee of Sun Pharmaceutical Industries, Inc. Meenal Kheterpal has participated on advisory boards for LEO Pharma and Sun Pharmaceuticals Industries, Inc.; and consulted for Spectrum Pharmaceuticals and Teladoc.

Compliance with Ethics Guidelines. Both studies in this post hoc analysis were performed in accordance with Declaration of Helsinki guidelines. After approval from institutional review boards for each study center, all patients provided informed consent before undergoing any study specific procedures.

Data Availability. All data generated or analyzed during this study are included in this published article/as supplementary information files.

Open Access. This article is licensed under a Creative Commons Attribution-NonCommercial 4.0 International License, which permits any non-commercial use, sharing, adaptation, distribution and reproduction in any medium or format, as long as you give appropriate credit to the original author(s) and the source, provide a link to the Creative Commons license, and indicate if changes were made. The images or other third party material in this article are included in the article's Creative Commons license, unless indicated otherwise in a credit line to the material. If material is not included in the article's Creative Commons license and your intended use is not permitted by statutory regulation or exceeds the permitted use, you will need to obtain permission directly from the copyright holder. To view a copy of this license, visit http://creativecommons.org/licenses/by$\mathrm{nc} / 4.0 /$. 


\section{REFERENCES}

1. Asgari MM, Moffet HH, Ray GT, Quesenberry CP. Trends in basal cell carcinoma incidence and identification of high-risk subgroups, 1998-2012. JAMA Dermatol. 2015;151(9):976-81.

2. Mohan SV, Chang AL. Advanced basal cell carcinoma: epidemiology and therapeutic innovations. Curr Dermatol Rep. 2014;3(1):40-5.

3. Apalla Z, Lallas A, Sotiriou E, Lazaridou E, Ioannides D. Epidemiological trends in skin cancer. Dermatol Pract Concept. 2017;7(2):1-6.

4. Kim JYS, Kozlow JH, Mittal B, Moyer J, Olencki T, Rodgers P. Guidelines of care for the management of basal cell carcinoma. J Am Acad Dermatol. 2018;78(3):540-59.

5. Peris K, Fargnoli MC, Garbe C, et al. Diagnosis and treatment of basal cell carcinoma: European consensus-based interdisciplinary guidelines. Eur J Cancer. 2019;118:10-34.

6. Amici JM, Battistella M, Beylot-Barry $\mathrm{M}$, et al. Defining and recognising locally advanced basal cell carcinoma. Eur J Dermatol. 2015;25(6):586-94.

7. Ally MS, Aasi S, Wysong A, et al. An investigatorinitiated open-label clinical trial of vismodegib as a neoadjuvant to surgery for high-risk basal cell carcinoma. J Am Acad Dermatol. 2014;71(5):904-11. e1.

8. Chang AL, Solomon JA, Hainsworth JD, et al. Expanded access study of patients with advanced basal cell carcinoma treated with the Hedgehog pathway inhibitor, vismodegib. J Am Acad Dermatol. 2014;70(1):60-9.

9. Epstein EH. Basal cell carcinomas: attack of the hedgehog. Nat Rev Cancer. 2008;8(10):743-54.

10. Odomzo (sonidegib capsules). Full prescribing information. Sun Pharmaceutical Industries, Inc., Cranbury, NJ, USA, 2017.

11. Erivedge (vismodegib capsules). Full prescribing information. Genentech, San Francisco, CA, USA, 2019.

12. European Medicines Agency. Summary of product characteristics, WC500188762, 2015.

13. Australian Government Department of Health, ARTG 292262, 2015.

14. Swissmedic, Authorization Number 65065, 2015.

15. DHPC - Erivedge ${ }^{\circledR}$ (Vismodegib). Swissmedic 2016.
16. European Medicines Agency. Summary of product characteristics, EMEA/H/C/002602.

17. Dummer R, Guminksi A, Gutzmer R, et al. Longterm efficacy and safety of sonidegib in patients with advanced basal cell carcinoma: 42-month analysis of the phase II randomized, double-blind BOLT study. Br J Dermatol. 2020;182(6):1369-78.

18. Migden MR, Guminski A, Gutzmer R, et al. Treatment with two different doses of sonidegib in patients with locally advanced or metastatic basal cell carcinoma (BOLT): a multicentre, randomised, double-blind phase 2 trial. Lancet Oncol. 2015;16(6):716-28.

19. Data on file. Sonidegib adverse events 21-month follow up. Provided by Sun Pharmaceuticals Industries Ltd, 2018.

20. Common Terminology Criteria for Adverse Events (CTCAE), Version 4.0. United States National Cancer Institute. 2010. https://evs.nci.nih.gov/ftp1/ CTCAE/CTCAE_4.03/CTCAE_4.03_2010-06-14_ QuickReference_8.5x11.pdf.

21. Hackshaw A. A concise guide to clinical trials. Chichester: BMJ Books; 2009. p. 224.

22. Altman DG, Bland JM. How to obtain the P value from a confidence interval. BMJ. 2011;343:d2304.

23. Dummer $\mathrm{R}$, Ascierto $\mathrm{P}$, Basset-Seguin $\mathrm{N}$, et al. Sonidegib and vismodegib in the treatment of patients with locally advanced basal cell carcinoma: a joint expert opinion. J Eur Acad Dermatol Venereol. 2020;34:1944-56.

24. Sekulic A, Migden MR, Basset-Seguin N, et al. Longterm safety and efficacy of vismodegib in patients with advanced basal cell carcinoma: final update of the pivotal ERIVANCE BCC study. BMC Cancer. 2017;17(1):332.

25. Lear JT. Oral hedgehog-pathway inhibitors for basal-cell carcinoma. N Engl J Med. 2012;366(23): 2225-6.

26. Basset-Séguin N, Hauschild A, Kunstfeld R, et al. Vismodegib in patients with advanced basal cell carcinoma: primary analysis of STEVIE, an international, open-label trial. Eur J Cancer. 2017;86: 334-48.

27. Dréno B, Kunstfeld R, Hauschild A, et al. Two intermittent vismodegib dosing regimens in patients with multiple basal-cell carcinomas (MIKIE): a randomised, regimen-controlled, doubleblind, phase 2 trial. Lancet Oncol. 2017;18(3): 404-12. 
28. Zollinger M, Lozac'h F, Hurh E, Emotte C, Bauly H, Swart P. Absorption, distribution, metabolism, and excretion (ADME) of ${ }^{14} \mathrm{C}$-sonidegib (LDE225) in healthy volunteers. Cancer Chemother Pharmacol. 2014;74(1):63-75.

29. Graham RA, Lum BL, Cheeti S, et al. Pharmacokinetics of hedgehog pathway inhibitor vismodegib (GDC-0449) in patients with locally advanced or metastatic solid tumors: the role of alpha-1-acid glycoprotein binding. Clin Cancer Res. 2011;17(8): 2512-20.
30. Goel V, Hurh E, Stein A, et al. Population pharmacokinetics of sonidegib (LDE225), an oral inhibitor of hedgehog pathway signaling, in healthy subjects and in patients with advanced solid tumors. Cancer Chemother Pharmacol. 2016;77(4):745-55. 